\title{
O que Fomos (África Pré-Colonial)? O que Fizeram de nós (Colonialismo)? O que Poderemos Voltar a Vir a Ser (Educação para a Descolonização dos Saberes)?
}

LOPES, Claudemira Vieira Gusmão

\section{RESUMO}

Nesta entrevista o mestre e professor Jayro Pereira de Jesus afirma que os negros e indígenas foram atravessados por um processo de enviesamento perpetrado pelo colonialismo. Dentre tantos prejuízos que o projeto colonial nos causou, ressalta a dualidade incrustrada dentro de cada um de nós. Desfazer e descolonizar nosso pensamento requer o exercício de outro projeto de escola, no qual a noção de ancestralidade é fundamental para promover a unidade de negros e negras na diáspora. Afirma também não podemos mais viver de concessões, caso da Lei 10.639. Precisamos de um projeto de educação afropedagógico e afrocentrado que trabalhe a concepção ancestrálica da filosofia africana como edificadora de outra comportamentalidade existencial capaz de uma reontologização. Essa noção de ancestralidade precisa ser retomada a partir do ubuntu, Filosofia Africana fundamentada no "nós", filosofia e epistemologia que entende a comunidade a partir dos vivos, dos ancestrais e a dos ainda não nascidos.

Educação. Filosofia africana. Racismo.

What were we (pre-colonial Africa)? What did they do to us (colonialism)? What can we become again (education for the decolonization of knowledge)?

\section{ABSTRACT}

In this interview professor and master Jayro Pereira de Jesus states that black and indigenous peoples were crossed by a bias process perpetrated by colonialism. Among the many losses to which the colonial project has subjected us, it highlights the inlaid duality within each and every one of us. Undoing and decolonizing our thinking requires the exercise of putting into practice another school project, in which the notion of ancestry, as it is the element that organizes interiorities and the way of perceiving and being in the world of the African people kidnapped from Africa regardless of ethnicity, it is essential to promote the unity

\footnotetext{
${ }^{1}$ Doutora em Ciências (UFPR). Professora Adjunta do Programa de Pós-graduação em Rede Nacional para Ensino das Ciências Ambientais da Universidade Federal do Paraná (UFPR). Email: clauvieiragusmao@gmail.com. Lattes: http://lattes.cnpq.br/1342667420502622. Orcid: https://orcid.org/0000-0001-5710-5434.
}

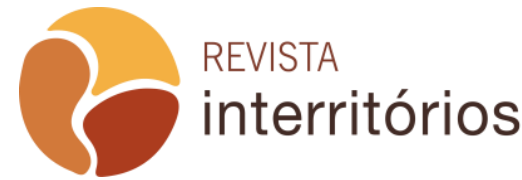


of black men and women in the diaspora. He also emphasizes that we can no longer live on concessions, such as Law 10.639. We need an Afropedagogical and Afrocentric education project that works with the ancestral conception of African philosophy as the builder of another existential behavioralism capable of a reontologization. This notion of ancestry needs to be taken up from Ubuntu, African Philosophy based on "us", philosophy, and epistemology that perceives the community that of the living, that of the ancestors, and that of the not yet born.

\section{Afrocentred Education. African Philosophy. Ancestrality and Epistemic Racism.}

\section{¿Qué éramos (África precolonial)? ¿Qué nos hicieron (colonialismo)? ¿En qué podemos volver a convertirnos (educación para la descolonización del conocimiento)?}

\section{RESUMEN}

En esta entrevista, el maestro y profesor Jayro Pereira de Jesús afirma que negros e indígenas fueron atravesados por un proceso de prejuicio perpetrado por el colonialismo. Entre tantas pérdidas que nos causó el proyecto colonial, destaca la dualidad incrustada dentro de cada uno de nosotros. Deshacer y descolonizar nuestro pensamiento requiere el ejercicio de otro proyecto escolar, en el que la noción de ascendencia es fundamental para promover la unidad de hombres y mujeres negros en la diáspora. También establece que ya no podemos vivir de concesiones, como en la Ley 10.639. Necesitamos un proyecto educativo afropedagógico y afrocéntrico que trabaje con la concepción ancestral de la filosofía africana como constructora de otro conductismo existencial capaz de reetología. Esta noción de ascendencia debe ser retomada de ubuntu, Filosofía africana basada en el "nosotros", filosofía y epistemología que entiende la comunidad desde los vivos, los ancestros y la de los no nacidos.

Educación. Filosofía africana. Racismo.

\section{Cosa eravamo (Africa precoloniale)? Cosa ci hanno fatto (colonialismo)? Cosa possiamo ridiventare (educazione alla decolonizzazione della conoscenza)?}

\section{SOMMARIO}

In questa intervista, il maestro e professore Jayro Pereira de Jesus afferma che i neri e gli indigeni sono stati attraversati da un processo di pregiudizi perpetrato dal colonialismo. Tra le tante perdite che il progetto coloniale ci ha causato, mette in luce la dualità intarsiata dentro ognuno di noi. Annullare e decolonizzare il nostro pensiero richiede l'esercizio di un altro progetto scolastico, in cui la nozione di ascendenza è fondamentale per promuovere l'unità degli uomini e delle donne di colore nella diaspora. Si afferma inoltre che non possiamo più vivere di concessioni, come nella Legge 10.639. Abbiamo bisogno di un progetto

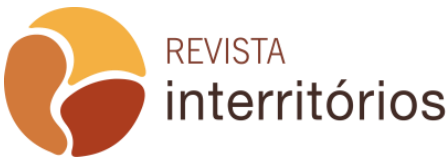


educativo afropedagogico e afrocentrico che lavori con la concezione ancestrale della filosofia africana come costruttore di un altro comportamentismo esistenziale capace di reetologia. Questa nozione di ascendenza deve essere ripresa da ubuntu, la filosofia africana basata su "noi", filosofia ed epistemologia che comprende la comunità dai vivi, dagli antenati e da quella dei nascituri.

Istruzione. Filosofia africana. Razzismo.

\section{INTRODUÇÃO}

O entrevistado é o professor e teólogo Jayro Pereira de Jesus (Olorode Ògìán Kálàfó2), que na visão da filósofa fundadora do Instituto Geledés, Sueli Carneiro, é um baluarte de resistência em torno da cultura, religiosidade e ancestralidade dos afrodescendentes. Nasceu na llha de Itaparica na Bahia, foi seminarista, estudou Filosofia e Teologia. Ao perceber a dualidade existente na teologia judaico-cristã e a descontinuidade fruto da desterritorialização e desenraizamento dos povos africanos, foi estudar Teologia da Tradição de Matriz Africana. Milita há muitos anos pela reontologização do povo africano em diáspora. Iniciou sua militância em $1980 \mathrm{com}$ a o trabalho Projeto Tradição dos Orixás, engendrado no Instituto de Pesquisa e Estudos da Língua e Cultura Yorubá (IPELCY), localizado $\mathrm{Na}$ Baixada Fluminense, que resultou na publicação do livro Tradição dos Orixás: valores civilizatórios afrocentrados, organizado pela Edilaine de Campos Gomes (UNIRIO) e Luis Claudio de Oliveira (UERJ), editora MADIDEIAS/Navegação Cultural e pelo Instituto de Pesquisa e Estudos Afro-brasileiros (IPEAFRO), 2019. Lutou contra o racismo religioso alvo da violência histórica e secular que os terreiros sofreram e sofrem na contemporaneidade por parte do Estado Nação/colonialidade (QUIJANO, 1988), no Estado Democrático e de Direito. Mapeou cerca de três mil terreiros na Baixada Fluminense, espraiando por todo Rio de Janeiro. No Paraná, atuou como consultor para assuntos filosóficos e religiosos no Grupo de Trabalho Clóvis Moura de 2006 a 2010 vinculado à Secretaria de Estado da Educação e à Secretaria de Estado da Cultura. Em 2012, ajudou fundar o Conselho de Povo de Terreiro do Estadual do Rio Grande do Sul ${ }^{3}$. Foi membro de uma equipe nacional da Fundação Palmares, coordenado pela socióloga Maria Dulce Pereira, socióloga, membra do Movimento Negro Unificado. O projeto foi coordenado pelo antropólogo Julio Braga e, posteriormente, realizou o mesmo trabalho em vários estados brasileiros, como Paraná, Santa Catarina, Rio

\footnotetext{
${ }^{2}$ De uma forma resumida, significa aquele que conhece a tradição e informa e socializa o que aprende.

${ }^{3}$ No III CONAPIR, em 2012, o Povo de Terreiro conclama um movimento político, na intenção da busca pela unicidade na representação nacional. Esta ação teve a participação do Teólogo Jayro Pereira de Jesus. (CUNHA, 2018).
} 
Grande do Sul, dentre outros. A bolsa de fellow e o fato de ser membro da Rede de Empreendedores Sociais da Ashoka, possibilitou grande parte deste trabalho, inclusive nacionalizando o projeto que iniciou na Baixada Fluminense. Realizou um mapeamento pela SEPPIR que resultou no livro Alimento: um direito sagrado, coordenando a pesquisa em Recife. Atualmente, é Coordenador da Escola Aldeia Ubuntu Vale do Akòko, localizado no município Mata de São João (Zona Rural da Região Metropolitana de Salvador, Bahia). Ele é um dos grandes críticos do Estado Nação no que se refere a educação ofertada aos meninos e meninas negros e negras.

Como o senhor percebeu que vivia numa sociedade racista e preconceituosa que trata os meninos e meninas negros e negras de forma profundamente desigual?

Para pensar o racismo que as crianças e jovens negros sofrem parto de um questionamento muito pessoal. Nasci na llha de Itaparica na Bahia e passei minha infância convivendo com vários pressupostos civilizatórios da filosofia africana, embora nem soubesse disso naquela época, esses valores serviram para que eu começasse a pensar nessas questões. Quando eu era menino e saía de casa para a escola ou outros afazeres sempre que encontrava uma pessoa adulta da comunidade (que era formada por homens, mulheres e crianças negras) ouvia a pergunta: menino você está indo para onde? Sua mãe sabe que você saiu? Você já se alimentou hoje? Eu ficava intrigado e pensava que tinha gente nos vigiando o tempo todo. Mais tarde isso fez sentido para mim. Porque dizia respeito aos valores africanos profundamente arraigados naquela comunidade. Outra coisa, é que além do controle do pai e da mãe na escola, havia também um controle por parte dos "ancestrais". Ouvia os mais velhos dizerem que nós crianças tínhamos que estudar porque os "eguns" poderiam aparecer a qualquer momento para saber sobre nosso desenvolvimento na escola. Não tínhamos luz elétrica naquela época na comunidade e, portanto, havia pouca influência dos meios de comunicação. Vivíamos o nosso cotidiano na eminência do aparecimento de uma ancestral que poderiam aparecer principalmente para resolver conflitos éticos, fato também observado em África

\footnotetext{
${ }^{4} \mathrm{Na}$ Tradição de Matriz Africana é o nome dado aos ancestrais que "voltaram para casa". Os Nagô separam as entidades em duas categorias bem definidas. De um lado estão os òrìsà, entidades divinas, e do outro, os ancestrais, espíritos de seres humanos. O òrìsà representa um valor e uma força universal; o égún, um valor restrito ao grupo familiar ou uma linhagem. Enquanto o òrisà interioriza no ser humano elementos da natureza e a sua presença a uma ordem cósmica, o égún interioriza a sua pertença a uma estrutura social limitada. Os òrìsà regulam as relações do sistema como totalidade; os égún, as relações, a ética, a disciplina moral de um grupo ou de um segmento. (SANTOS, 1986, p.104).
}

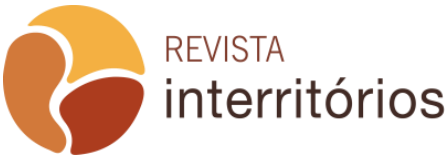


mesmo no pós-colonialismo ${ }^{5}$. Na minha juventude fui estudar no Mosteiro de Jequitibá, com monges cistercienses em Mundo Novo. Essa organização religiosa foi fundada em 1939 por monges que pertencem à Ordem de Cister, vindos de Schlierbach na Áustria. Meu trabalho era na biblioteca. Então, tive acesso a muito conhecimento que ajudaram responder muitas das minhas indagações filosóficas. Mas teve um fato nesse mosteiro que me fez romper com a filosofia, a ciência ocidental e com a igreja católica. Nós éramos onze meninos estudando no mosteiro, nove meninos brancos e dois negros, eu e outro rapaz. Os monges enviaram os nove meninos brancos para estudar na Europa, apenas eu e o outro menino negro, não fomos enviados para estudar fora. Na ocasião, questionei os monges. Percebi o racismo, o preconceito e a discriminação naquela atitude deles e resolvi romper com a igreja católica. A partir desse momento saí em busca de respostas para os meus questionamentos. Imbuído de uma atitude filosófica, sob o ponto de vista da filosofia africana, comecei a me perguntar: O que fui ou o que éramos (em África pré-colonial)? O que fizeram de nós (no colonialismo)? O que poderíamos voltar a vir a ser na decolonialidade? Foi pensando a partir dessa outra forma de conceber o mundo, de me relacionar com as pessoas, de pensar a economia, o amor e a afetividade que fui buscar entender essas e outras questões. Tudo isso me levou a outra questão que me atormentou durante muito tempo: a impressão de que nós negros sobrevivemos na diáspora em meio a uma incompletude civilizatória. Fui buscar respostas na filosofia Ubuntu que não é cartesiana, não "penso logo existo", "eu penso e logo me lembro dos que me antecederam, dos que estão aqui hoje e dos que haverão de vir e é por isso que eu existo"6 lendo filósofos e teóricos africanos como Mogobe Bernad Ramose ${ }^{7}$, Marcien Towa ${ }^{8}$, Kabengele Munanga ${ }^{9}$, Achille Mbembe $^{10}$,

\footnotetext{
${ }^{5}$ Para Achille Mbembe o colonialismo foi um projeto de universalização, cuja finalidade era "inscrever os colonizados no espaço da modernidade". Porém, a "vulgaridade, a brutalidade tão habitualmente desenvolta e sua má-fé fizeram do colonialismo um exemplo perfeito de antiliberalismo". (ALMEIDA, 2019).

${ }^{6}$ Para Ramose, Ubuntu é ao mesmo tempo uma filosofia, uma ontologia e uma ética, trata-se da filosofia do nós. A comunidade é entendida como lógica e historicamente anterior ao indivíduo, definida como uma "entidade dinâmica"presente em três esferas: a dos vivos, a dos mortos-vivos ("ancestrais") e a dos não nascidos. O indivíduo não perde sua autonomia e sua liberdade. A origem do Ubuntu está na linguagem (ação e escrita) e no pensamento.

(SARDELOTTO; SANDER, 2010).

${ }^{7}$ Doutor em filosofia pela Katholiev Universiteit Leuven (Bélgica), pesquisa filosofia africana, filosofia política e direito e relações internacionais. Trabalhou na Universidade do Zimbábue e Venda na África, atualmente é professor de filosofia na Universidade da África do Sul, escreveu vários livros, dentre eles, African Philosophy Trhough Ubuntu.

${ }^{8}$ Filósofo camaronês, que nos instiga a questionar o absoluto (a verdade). Escreveu o livro "A ideia de uma filosofia negro-africana.

${ }^{9}$ Antropólogo brasileiro-congolês, professor da USP. É especialista em antropologia da população afro-brasileira, atentando-se a questão do racismo na sociedade brasileira.

${ }^{10}$ Filósofo, teórico político, historiador, intelectual e professor universitário camaronês. Autor de "Necropolítica" e "Crítica da Razão Negra".
}

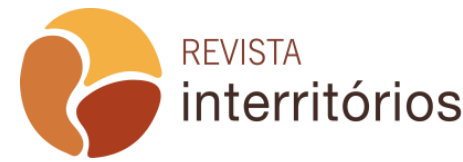


Carlos Moore ${ }^{11}$, Cheikh Anta Diop ${ }^{12}$, Théophile Obenga ${ }^{13}$, Franz Fanon ${ }^{14}$, Amadou Hampâté Bá ${ }^{15}$, Joseph Ki-Zerbo ${ }^{16}$ e pensadores e pensadoras brasileiros/as como Sueli Carneiro ${ }^{17}$ e Muniz Sodré ${ }^{18}$.

\section{Como o senhor resolveu essa questão da incompletude civilizatória?}

Fui estudar a história da escravidão para entender, por exemplo, a faixa etária das pessoas trazidas compulsoriamente de África para o Brasil pelo colonialismo $^{19}$. Descobri que a maioria das pessoas sequestradas naquela época eram jovens que ainda não possuíam os valores civilizatórios africanos

\footnotetext{
${ }^{11}$ Antropólogo com dupla nacionalidade cubana e jamaicana. Doutor em Ciências Humanas e Doutor em Etnologia pela Université de Paris - 7, atua como Chefe de Pesquisa Sênior (Honorário) da Escola de Estudos de Pós-Graduação e Pesquisa da University of the West Indies (Jamaica). Escreveu vários livros e artigos, dentre eles, "Racismo \& Sociedade: novas bases epistemológicas para entender o racismo".(MOORE, 2007).

${ }^{12}$ Historiador, químico, físico, arqueólogo e antropólogo senegalês que estudou as origens da raça humana e a cultura africana pré-colonial. Foi considerado um dos maiores historiadores africanos do século XX. Fundou e dirigiu o Laboratório de Radiocarbono do Instituto Fundamental da África Negra (IFAN) da Universidade de Dakar no Senegal, abalou os círculos científicos com suas teses defendidas em 1955, 1959 e 1967. Escreveu vários livros, dentre eles, "The African Origin of Civilization: myth or reality". (NASCIMENTO, 2008).

${ }^{13}$ Congolês, discípulo e amigo de Cheikh Anta Diop, tem defendido uma perspectiva da história africana reorientada para as preocupações dos investigadores e intelectuais africanos, ansiosos por revisitar a sua herança cultural, dentre eles, "O sentido da luta contra o africanismo eurocentrista.

14 intelectual martinicano, psiquiatra, militante negro, autor da expressão "descolonização das mentes", Frantz Fanon é destaque no pensamento negro desde o século 19, com escritos traduzidos em mais de dez línguas, escreveu "Os Condenados da Terra" e "Peles Negras e Máscaras Brancas".

${ }^{15}$ Participou da elaboração dos primeiros estudos que usam as fontes orais de maneira sistemática, como em "História Geral da África", publicada pela Unesco em 1980.

${ }^{16}$ Formado em História pela Universidade de Sorbonne em Paris, Foi membro do Comitê Científico para a elaboração da História Geral da África pela UNESCO em oito volumes e diretor do primeiro volume, Méthodologie et préhistoire africaine lançado em 1981.

${ }^{17}$ Filósofa, escritora e ativista brasileira. Trabalha com o conceito de epistemicídio: " o fenômeno que ocorre pelo rebaixamento da autoestima que o racismo e a discriminação provocam [...]; pela negação aos negros da condição de sujeitos de conhecimento, por meio da desvalorização, negação ou ocultamento das condições do continente africano e da diáspora africana ao patrimônio cultural da humanidade; pela imposição do embranquecimento cultural e pela produção do fracasso escolar. A esses processos denominamos epistemicídio."

${ }^{18}$ Muniz Sodré de Araújo Cabral é professor Titular da Universidade do Rio de Janeiro, Pesquisador do Cnpq. Tem 36 livros publicados sobre comunicação, cultura e ficção, alguns traduzidos na Itália, Espanha, Argentina e Cuba. É professor visitante de várias universidades estrangeiras, membro do llê Axé Opô Afonjá na Bahia. (SODRÉ, 2012).

19 "O colonialismo clássico baseava-se na exploração territorial, econômica e política dos povos submetidos pela força das armas. A exploração deu lugar à dominação: hoje, persiste aquilo que em determinados círculos de estudos pós-coloniais costuma-se chamar de colonialidade, ou seja, a dominação de caráter cultural, que nega igualdade, que nega igualdade ao diferente." (SODRÉ, 2012, p. 42).
}

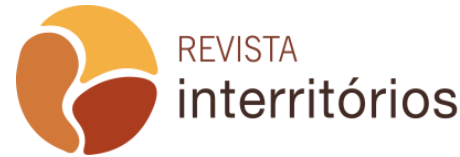

Interritórios | Revista de Educação Universidade Federal de Pernambuco, Caruaru, BRASIL | V.6 N.12 [2020] 
consolidados $^{20}$. E aí fui tendo a certeza de que o processo de violência do colonialismo foi fundamentalmente um processo de desontologização. O estrago e a violência só foram possíveis porque primeiro se trabalhou com a destituição do sentido de ser do Outro. Como é sobreviver em meio a uma subjetividade e subjetivação fruto de uma violência? Porque a sociedade branca ocidental capitalista se guarda, se orienta e institui todas as suas violências a partir desse tempo chamado colonialidade. Isso me perturbava muito. O João José Reis ${ }^{21}$ foi o historiador que conseguiu traduzir e trazer à tona o que chamo de consubstancialidade ancestral porque a pesquisa dele é voltada para esse tema (substancialidade civilizatória) e recentemente, em um livro chamado "Racismo em português: o lado esquecido do colonialismo", a jornalista Joana Gorjão Henriques $^{22}$ me ajudou compreender como o amalgamento afrofilosófico foi

\footnotetext{
${ }^{20}$ Para saber mais sobre como os valores civilizatórios africanos estão baseados na filosofia Ubuntu. Ler KASHINDI, J-B. K. Ubuntu como ética africana, humanista e inclusiva. Disponível em: http://www.ihu.unisinos.br/images/stories/cadernos/ideias/254cadernosihuideias.pdf. Acesso em: 21/09/2020. [...] na maioria das sociedades africanas, os idosos são os verdadeiros fundamentos da aldeia. Além disso, costuma-se dizer que uma aldeia sem idosos é como uma cabana devorada por cupins. O respeito pelo qual eles vivem cercados se deve não apenas à sua longevidade - fenômeno raro na África - mas devido à concepção animista africana do universo, segundo a qual a vida é uma corrente eterna que flui através dos homens em gerações sucessivas. Desde antes do nascimento do africano, ele já pertence a uma linhagem, faz parte de um grupo, não pode ser separado daqueles que o precederam ou daqueles que 0 seguirão, e os valores tradicionais o protegerão na velhice contra a abandono e solidão. Dentro dessa concepção africana de mundo, ligada à noção de força vital, a idade avançada constitui um estágio da existência humana a que todos aspiram. De fato, devido à fé na sobrevivência, na continuidade da vida e no culto aos antepassados, os idosos ocupam uma posição privilegiada porque constituem o elo entre os ancestrais vivos e os mortos. Essa eternidade da vida é concebida na forma de um movimento circular que vai do nascimento à morte e vice-versa. Assim como a criança está destinada a ser um adulto, 0 adulto um idoso e o idoso um ancestral, a criança renascerá como uma força vital para completar o círculo da vida. Segundo a concepção ambún do universo, após a morte, começa a vida invisível dos espíritos, isto é, dos ancestrais. KABWASA, N. O. O eterno retorno. In: O Correio da Unesco (Brasil), dez. 1982, ano 10, n.12, p.14 -15.

${ }^{21} \mathrm{Um}$ dos mais importantes historiadores do Brasil, referência mundial para o estudo da história e da escravidão no século XIX. Escreveu diversos livros, dentre eles "A morte é uma festa" (Prêmio Jabuti de Literatura). É graduado em história pela Universidade Católica de Salvador, tem Mestrado e Doutorado pela Universidade de Minnesota, vários pós doutorados, que incluem a Universidade de Londres, o Center for Advanced Studies in the Behavioral Sciences, Universidade de Stanford e o National Humanities Center. Advanced Studies in the Behavioral Sciences da Universidade de Stanford. Também foi professor visitante das seguintes universidades: Universidade de Michigan, Universidade Brandeis, Universidade de Princeton, Universidade do Texas e Universidade de Harvard. Atualmente é professor titular do departamento de história da Universidade Federal da Bahia. (ALBUQUERQUE JÚNIOR, 2009). 22 Joana Gorjão Henriques é uma jornalista portuguesa que escreve para o Jornal O Público. Ela propôs à direção do jornal um projeto de cinco reportagens, que ela chamou de "Racismo em Português," nas cinco ex-colônias africanas para questionar a herança colonial.

Acompanhada por um historiador, realizou uma visita guiada a lugares históricos dos países colonizados em busca de uma possível Rota da Escravatura. Disponível em: https://www.geledes.org.br/racismo-em-portugues-o-lado-esquecido-do-colonialismo/. Acesso em: 21/09/2020.
}

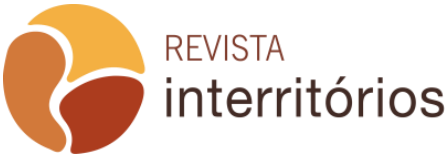


possível. Percebi que isso aconteceu principalmente no translado transatlântico, sendo a língua a possibilitadora de uma amalgamento civilizatório. Essa autora fala que "o racismo colonial foi um apagão e um arrastão: apagão da cultura africana, obrigando as populações a despirem-se de toda a sua identidade; e um arrastão ideológico, porque contaminou mentalidades de todos os quadrantes e durante séculos, e de tal forma que até hoje se verificam seus efeitos." Dito de outra forma, o colonialismo destituiu elementos ontológicos fundamentais que estruturavam e organizavam a existência dos africanos. O colonialismo destituiu isso numa ação de desexistencialização e o que ela chama de arrastão ideológico, permeou o imaginário ontologicamente destruindo outros pressupostos, sobretudo promovendo a dualidade e o maniqueísmo. Esses elementos é que sustentam a intolerância religiosa e o racismo religioso na contemporaneidade. Observo que muitas das falas de sacerdotes das religiões de matriz africana ainda são ontologicamente superficiais porque não apontam para uma ação de negação do racismo com uma substancialidade negroafricana. Estamos sempre sobrevivendo em meio as arapucas e armadilhas do colonialismo. Somos pretos por fora, mas a nossa subjetividade, a nossa interioridade é branca e ocidental. A violência causada pelo apagão e arrastão produziu um Outro cuja humanidade foi concedida a partir da negação da própria existência. Gosto do livro do Muniz Sodré, grande pensador negro brasileiro, que trabalha com a noção de complexo que a Juana Elbein dos Santos ${ }^{23}$ chama de nexo ontogenético e ele aprofunda no livro "Pensar Nagô24", ele diz: "O semiocídio ontológico perpetrado pelos evangelizadores foi o pressuposto físico" que vocês podem ampliar para genocídio mental e existencial. Semiologia é a ciência dos sentidos dos valores, dos elementos que organizam o significado das coisas.

O senhor saiu pelo Brasil afora mapeando os terreiros e lutando contra o racismo e a intolerância religiosa. Qual foi sua principal bandeira para combater o racismo religioso ou intolerância religiosa?

Essa luta de tentar mostrar que a Tradição dos Orixás não contempla apenas o aspecto religioso não é só minha. Entendo que na diáspora das Américas, o que era antes do colonialismo, uma forma de ver, de ser e de estar no mundo, ao atravessar o Atlântico, tomou esse contorno religioso. Antes mesmo da deportação dos africanos para as Américas, o colonialismo usou essa estratégia do esvaziamento dos elementos ontológicos para subalternizar os africanos. Uma vez destruído isso ficou muito fácil destruir os outros pressupostos. A Igreja

${ }^{23}$ SANTOS, J. E. dos. Os nagô e a morte: pàde, àsèsè e o culto égun na Bahia. Petrópolis, RJ: Vozes, 1986.

${ }^{24}$ SODRÉ, M. Pensar nagô. Petrópolis, RJ: Vozes, 2017, p.102.

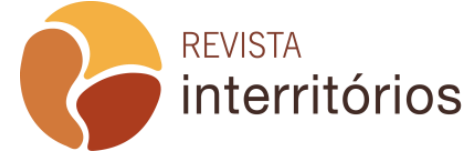


Católica teve papel preponderante nesse processo num período em que se confundia relações sociais com religião. A visão maniqueísta, dicotômica contaminou as relações sociais com a ideia do mal e do bem, são as armadilhas e arapucas do colonialismo que persistem até hoje, fundamentando o racismo cultural religioso. De quais valores e/ou pressupostos da cosmovisão africana estou me referindo? Nesse modo de ver o mundo o corpo é considerado território do sagrado. A existência é concebida como ligada ao todo, ao cosmo, à natureza. Os termos usados na diáspora como orixá25, inquice e vodum na verdade representam a constituição do ser e da subjetividade. Na diáspora virou incorporação e a Tradição de Matriz Africana se ressignificou e hoje compreende várias articulações, assumido em uma disputa de poder ou para se adequar à essa relação de poder estabelecida. Essa relação de colocar o Outro como insignificante, com uma humanidade concedida por causa da violência do colonialismo, fez com que os africanos buscassem várias formas de manter sua identidade e não perder os valores que os sustentavam. Então, orixá é subjetividade, aquilo que te integra e estrutura. Infelizmente, na diáspora se reduziu à incorporação, assumindo essa visão perniciosa e dual do maniqueísmo (bem e mal). Na minha concepção trata-se de uma forma de ser, constitui a existência, não é algo esporádico que de vez em quando se manifesta e depois vai embora. Ele é o indivíduo (homem ou mulher). Então, entendo que conceber o ser humano do ponto de vista africano é compreendê-lo como detentor de uma sacralidade existencial, é o que estruturaliza e dá sentido à vida. Dito de outro jeito, é uma forma de ser. Essa forma como a divindade se manifesta que se reconstruiu no Brasil é uma criação afrodiaspórica. Penso que é nos terreiros de candomblé que estão guardados de forma amalgamada os saberes e princípios e valores da filosofia africana. O que chamam de iniciação nos terreiros, entendo como um processo de cosmologização. O ser humano do ponto de vista das culturas africanas quando está sendo gerado no ventre da mãe está ligado ao Todo, ao nascer, se desliga e precisa se ligar novamente a esse Todo. Para isso há que se oportunizar um útero mítico para que essa relação com o Todo possa então ser restabelecida. Por isso, não gosto dessa expressão "fazer o santo" que é uma visão ocidental, ou seja, pertence a outro universo religioso que não é africano. Acredito que os terreiros têm esse papel de repensar essa visão reducionista porque o terreiro é o lugar de reconstrução civilizatória. Essa visão reducionista à qual me referi é que alimenta o racismo e a intolerância religiosa

\footnotetext{
25 "Se os pais e antepassados são os genitores humanos, os òrìsà são os genitores divinos; um indivíduo será "descendente" de um òrìsà que se considera seu "pai" - Baba mi - ou sua "mãe" - lyá mi - de cuja matéria simbólica - água, terra, árvore, fogo etc. - ele será um pedaço [...]. Assim, como nossos pais são nossos criadores e ancestres concretos e reais, os òrìsà são nossos criadores simbólicos e espirituais, nossos ancestres divinos. Assim cada família considerará um determinado òrìsà como o patriarca simbólico e divino de sua linguagem, sem o confundir com seus égún patriarcas e genitores humanos, cultuados em 'assentos', em datas e de formas bem diferenciadas. (SANTOS, 1986, p104 - 104).
}

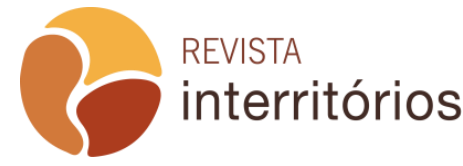


que venho combatendo nas minhas andanças Brasil afora. Se o colonialismo destruiu a possibilidade de enunciação ontológica do sacerdote, que na diáspora recebeu o nome de "Pai e ou Mãe de Santo", de Tradição de Matriz Africana é preciso repensar tudo isso. Entendo que na luta contra o racismo religioso $o$ papel do terreiro na diáspora é de reconexão, de cosmologização e de organização existencial. Se o roncó ${ }^{26}$ não for o útero mítico de reconstrução de uma existência vilipendiada, se torna um lugar de cárcere privado. $O$ terreiro deve possibilitar ao ser humano afrodescendente o que the foi impossibilitado de ser. A ancestralidade não é valor patrimonial de ninguém. Penso que para ser "Pai" ou "Mãe de Santo" a pessoa precisa estudar e ser estruturada emocionalmente, conhecer o processo histórico para possibilitar a reconexão. Além do mais os terreiros precisam, devem ser um local de educação não formal, recebendo as pessoas para a formação teológica, proporcionando autonomia e liberdade dentro dos parâmetros da filosofia africana. É preciso perceber que subjetividade é ancestrálica.

O senhor é um grande crítico do projeto de educação ofertada aos meninos e meninas negros e negras aqui no Brasil porque no seu modo de ver trata-se de modelo de educação fragmentado e ocidentalizado e, sendo assim não contribui para a reontologização da população negra e ou/indígenas brasileira. Nesse sentido, poderia falar um pouco sobre o seu entendimento da categoria Educação Afroindígena?

Verdadeiramente os substanciais resquícios do colonialismo que potencialmente interage na dinâmica do Estado-Nação ${ }^{27}$ e/ou na colonialidade do poder (QUIJANO, 1998), como numa correlação a prevalência do Colonialismo interno

\footnotetext{
${ }^{26}$ Local onde o iniciado fica recolhido enquanto dura o processo de feitura do santo. (SANTOS, 1986).

${ }^{27}$ Nações e Estados não são fenômenos novos. Entretanto, o que Quijano (1998) chama de moderno Estado-nação é uma experiência muito específica. Diz respeito a uma sociedade nacionalizada e politicamente organizada como um Estado-nação. Contempla as instituições modernas de cidadania e democracia política. Dito de outra forma, implica uma certa democracia, "dado que cada processo conhecido de nacionalização da sociedade nos tempos modernos ocorreu somente através de uma relativa (ou seja, dentro dos limites do capitalismo) mas importante e real democratização do controle do trabalho, dos recursos produtivos e do controle da geração e gestão das instituições políticas. Deste modo, a cidadania pode chegar a servir como igualdade legal, civil e política para pessoas socialmente desiguais" (QUIJANO, 1998). Pode-se considerar um Estado-nação como uma espécie de sociedade individualizada entre as demais. Nesse sentido, pode ser considerada como identidade entre seus membros. Se toda sociedade é uma estrutura de poder, e poder é aquilo que articula formas de existência social dispersas e diversas numa totalidade única, ou seja, uma sociedade. Logo, podemos inferir que toda estrutura de poder é sempre, parcial ou totalmente imposta aos demais grupos. Dito de outra forma, do modo como foram configuradas as disputas pelo controle do trabalho, seus recursos e produtos; do sexo, seus recursos e produtos; da autoridade e de sua violência específica; da intersubjetividade e do conhecimento. (QUIJANO, A. "La nueva heterogeneidade estructural de América Latina"em Sonntag; In: HEINZ (ed.). Nuevos temas, nuevos contenidos. Caracas: UNESCO/Nueva Sociedad, 1988.
}

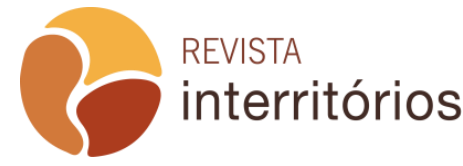

Interritórios | Revista de Educação Universidade Federal de Pernambuco, Caruaru, BRASIL | V.6 N.12 [2020] 
ao poder racista/etnicista engendrado pelo Colonialidade que opera nos interstícios do Estado-Nação ${ }^{28}$, como assim referem-se Pablo Gonzalez e Rodolfo Stavenhagen (Apud QUIJANO, 2010), tem sido o impedidor, da viabilização de uma educação que reforce ou reconstitua a dinâmica existencial de forma plena dos Povos Indígenas e Africanas/os na dispersão pelas Américas, denotando o diferencial epistemológico dos Povos Indígenas, singularizado na Lei de Diretrizes e Base da Educação Nacional Brasileira (LDB) que atualmente vem sendo alvo da xenofobia ${ }^{29}$ do atual governo nacional que atentam contra direitos civilizacionais dos segmentos autóctones, bem como do contingente desterritorializado ${ }^{30}$ e desenraizado do continente africano que junto com a mão de obra compulsória dos nativos originalmente, construíram a bases, fundamentalmente econômica e cultural do país, prosseguindo na dinâmica e estratégia de resistência ante a hegemonia judaico/ cristã/ocidental/epistêmica e de uma filosofia cartesiana que alimenta na contemporaneidade todo um ideário persistente inarredável de subalternidade, inferioridade existencial cuja política de semiocídio ${ }^{31}$ e genocídio prossegue inalterado.

\footnotetext{
${ }^{28}$ Ainda sobre o conceito de Estado-Nação abordado pelo professor Jayro vale a pena ler Muniz Sodré (2012) quando afirma que a Europa é o berço do Estado-nação, sendo esse continente constituído pela imposição (monoculturalista) de uma língua única, em detrimento das demais e em contraste com a realidade dos Estados-nação de outros continentes (a África é um exemplo de heterogeneidade no que diz respeito a imensa quantidade de línguas). (SODRE, 2012, p.24).

${ }^{29}$ Para entender o significado do termo xenofobia empregado aqui pelo professor Jayro, sugiro a leitura do capítulo 2, p.55 do livro Racismo \& Sociedade: novas bases epistemológicas para entender o racismo de Carlos Moore, quando o autor problematiza: Xenofobia ou Protoracismo? "Gregos e romanos constituíram um mundo alicerçado sobre a explícita distinção dos seres humanos entre 'inferior' e 'superior', 'bárbaros' e 'civilizados'; e mais, entre aqueles que 'nascem para serem escravos' e os que 'nascem para serem livres'. De todo modo, no início não parece ter havido correspondência sistemática entre essa precoce hierarquia baseada na escravidão, que parece ser intrínseca à maioria dos povos da Antiguidade, e uma noção de 'superioridade' e 'inferioridade' inatas com conotação puramente racial." (MOORE, 2007, p.55). "Sabe-se que tanto os gregos quanto os romanos eram profundamente xenófabos, considerando automaticamente como 'bárbaros' todo e qualquer estrangeiro, e que tanto Grécia quanto Roma se basearam na escravidão como modo principal e dominante de produção. Salvo em raras ocasiões, os escravos do mundo greco-romano eram brancos europeus, considerados bárbaros. Em princípio, enquanto a dominação greco-romana não se estendeu para fora da Europa, as definições de 'superior' e 'inferior', 'livre' e 'escravo', 'civilizado' e 'bárbaro' foram aplicadas exclusivamente a populações vizinhas de raça branca. Isso mudaria significativamente com a extensão do imperialismo helenístico e romano ao norte da África e ao Oriente Médio." (MOORE, 2007, p.55).

${ }^{30}$ Sodré (2019, p.115) diz que "Na História real, a escravidão implicou sempre uma desterritorializaçãp, isto é, um desenraizamento de indivíduos, transplantados de seu lugar próprio para a organização de um outro, que os fazia experimentar a morte da origem".

${ }^{31}$ Diz-se da ação em que se desrespeita a alteridade como característica maior da espécie humana, uma vez que se apropria dos símbolos do Outro a partir de uma ressemantização negativa. (SODRÉ, 2005).

Em Pensar Nagô, Muniz Sodré retoma novamente esse termo para afirmar que "a violência civilizatória da apropriação material era na verdade, precedida pela violência cultural ou simbólica - uma operação de 'semiocídio', em que se extermina o sentido do Outro - da catequese monoteísta, para qual o corpo exótico era destituído de espírito, ao modo de um
}

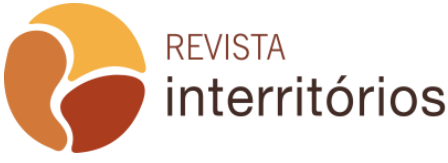

Interritórios | Revista de Educação Universidade Federal de Pernambuco, Caruaru, BRASIL | V.6 N.12 [2020] 
Por que o senhor afirma que a noção de ancestralidade é fundamental para a unidade na diáspora?

A despeito dos diversos grupos étnicos e das supostas diferenças culturais e dos antagonismos atribuídos entre as dinâmicas culturais das etnias africanas transladadas para as Américas, me empenhei diuturnamente, buscar entender o diferencial humano-existencial dos referidos povos, a exemplo da noção e/ou auto concepção, perscrutando que a ideia de ancestralidade não se atinha a uma referencial que funciona inerente e indissociavelmente aos povos africanos, com ênfase à região subsaariana. Compreendo que ancestralidade corporifica a dinâmica existencial, a estruturando e dando-lhe sentido como uma substancialidade organizadora da interioridade e que nas dispersões transatlânticas converteram-se em divindades desagregadas da Existência, da Vida, do Ser como num complexo dualizado, maniqueizado ou dicotômico. Assim, portanto, a arapuca ou armadilha pós-colonial a que foi e está subtraída a Cosmo Afro-Existencialização na esfera da religião, adequando-se ao maniqueísmo judaico-cristão, sustentáculo do racismo religioso, racismo cultural religioso, como assim me referi no passado (JESUS, 2003). Devido a essa compreensão tenho pensando e ainda muito cuidadosamente, abordado a dimensão da bioafroancestralidade como condição configuradora da intersubjetivação afrodiaspórica, fator que enxergo como determinante para um processo de reconstrução e de interiorização, de uma outra e antagônica ideia de subjetividade que se opõe à ideia judaico cristã ocidental com seus aparatos psicológicos e psicanalíticos de conceber 0 ser humano. A bioafroancestralidade, corolário da intersubjetivação afrodiaspórica, em absoluto reconfigurará a unidade da população preta em África hodierna e nas suas diásporas.

O que o senhor quer dizer com "os negros e indígenas sofreram um processo de enviesamento?

O colonialismo operacionalizou um enviesamento existencial dos povos invadidos, através das mais variadas e sistemáticas violências materiais e simbólicas. O semiocídio ontológico, o qual se refere Sodré (2020) igualmente operacionalizou o semiocídio kratofônico que o filósofo Eboussi Boulaga, citado por Enrique Dussel (2012) assevera: "a língua é uma manifestação da força, do Poder Originário; é uma kratononia [...]. Manifesta a força que move as superfícies. O de dentro se expõe no fora, o fora retorna ao dentro". Como

receptáculo vazio que poderia ser preenchido pelas inscrições representativas do verbo cristão". (SODRE, 2020, p.101-102).

\begin{tabular}{l|l} 
REVISTA & Interritórios | Revista de Educação \\
interritórios & $\begin{array}{l}\text { Universidade Federal de Pernambuco, } \\
\text { Caruaru, BRASIL | V.6 N.12 [2020] }\end{array}$
\end{tabular}


sinonímia de enviesar, se conota envesgar, virar entortar, revirar, torcer, atravessar, traçar, quebrar; em-vi-e-sar: cortar de viés por de viés, entortar, da má direção andar ou tomar de viés; tomar má direção, envergar. Ou seja, essa destituição do Outro ontológico foi também um semiocídio kratofônico à medida que o Ocidente impôs sua língua como única possibilidade para estabelecer a comunicação entre os povos traduzindo-se num processo de violência civilizatória terrível. Os negros e os indígenas passaram por esse processo de enviesamento. Para desfazer isso só com uma educação que parta de outra perspectiva filosófica. Porque como afirma Sodré (2012) a escola é uma forma moderna, ao lado de outras (nação, mercado etc.) por onde não só se introduz saberes, mas se estabelecem conexões entre eles, metabolizando os parâmetros de reprodução do sistema racista, colonial e capitalista. Precisamos subverter essa ordem social, exercitando paralelamente outro projeto de educação e, para isso, desenvolver a noção de ancestralidade é fundamental na diáspora.

O senhor afirmou em uma entrevista que a esquerda brasileira é branca e faz concessões e que a Lei 10.639/2003 seria um exemplo dessa concessão. Como assim?

Desde sempre compreendi esse papel do Estado-Nação que está dimensionado na Colonialidade do Poder e de outros sustentáculos da subalternidade, configurando as/os Condenados da Terra (FANON, 1979). Nessa esteira seguem as colorações partidárias do Estado-Nação em que pese o que se compreenda como direita ou esquerda. A direita evidentemente comunga com ideário da subalternização da alteridade não europeia, enquanto a dita esquerda faz suas concessões que a sociologia e a antropologia das relações não alteram substancialmente. Assim, entendo que suposta abertura aos movimentos sociais e a implementação das políticas públicas funcionam tão somente como distencionamentos, apaziguamentos dos ânimos sociais mais atentos dos pseudos representantes de organizações ativistas das lutas antirracistas etc.

\section{O que é Pedagogia da interioridade ancestrálica?}

Cada vez mais estou convencido que a escola pública estruturada e mantida pelas esferas executivas e as ações legislativas e as supostas iniciativas inovadoras no campo da educação, baseadas em pressupostos eurocêntricos, funcionam pedagogicamente na reificação do não-ser invariavelmente. A ancestralidade e a intersubjetividade afrodiaspórica para a pessoa de origem africana a ancestralidade é uma condição de existência, não é algo desacoplado que acoplo e desacoplo. É o fundamento aglutinador capaz de possibilitar a bio-

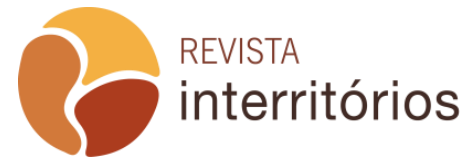


preto-ancestralidade. Nesse sentido, o pensar e fazer-sendo afrofilosoficamente é o que impulsiona a Escola Aldeia Ubuntu Vale do Akòko, que está sendo construída na região metropolitana de Salvador (BA), no bairro Amado Bahia, no município de Mata de São João. A Afropedagogia da Interioridade Ancestral, se ampara em determinantes conceituais, teóricos, metodológicos de maneira a responder à seguinte problemática: $O$ que fomos ou éramos; o que fizeram de nós e o que poderemos voltar a vir a Ser, desreligiolizando as reminiscências afrodiaspóricas, que como sobrevivência ancora-se como performance como simulacração, em que adereços e alegorias inscrevem-se como dissimulação Existencial. Afropedagogia da Interioridade Ancestral, se fundamenta nos pressupostos da xenofilia radicalmente adversa aos mecanismos da xenofobia determinantes das políticas, da cultura, da visão capitalista e da globalização.

Em uma de suas palestras, citando Dussel, o senhor afirmou que "a filosofia é um dos símbolos institucionais que o Ocidente transportou para fora de si e ofereceu como forma de assimilar os outros. Tudo começa quando mutum ${ }^{32}$, o ser humano experimenta o naufrágio de sua palavra afogada na insignificância, na possibilidade do não significativo. Isso acontece quando se fala e já não se faz compreender, como um animal que grunhe ou um bárbaro que balbucia". Qual o significado dessa afirmação para os afrodescendentes?

A assertiva de Dussel (2010) se traduz numa dialogia com Eboussi Boulaga que confirma a ideia hegemônica do Ocidente, situando-a como uma prática autoritária, que notabiliza a filosofia como grega-europeia de forma a descredibilizar outras culturas, fundamentalmente as filosofias africanas, desconsiderando as suas invariáveis, legitimando o colonialismo, justificando a universalismo como particularidade do europeu. É assim que o Ocidente continua nos enxergando. O mutum vive tomando consciência do que se tornou, do que a violência da história fez dele; vive comprovando a inutilidade da apologética, dito de outra forma, vive comprovando a inutilidade da capacidade de afirmar elementos pressupostos de sua existência.

Nessa perspectiva, o que é ser humano?

Volto a referir-me a dimensão bioafroancestrálica da Existência no ideário da filosofia africana que entendo como detentor de uma relação com o Todo que tipifico como Cosmo Afro-Existencialização. Mulheres e homens (Ser Humano) num intrínseco imbricamento ontológico, epistemológico e ético. Detentor de uma "sacralidade" Existencial, que não pensa logo existe cartesianamente

32 Significa ser humano na língua kicongo,

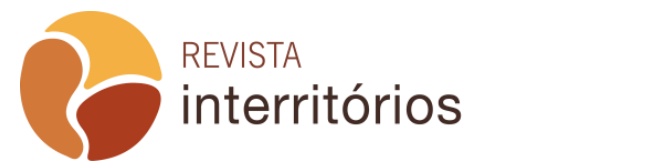


falando. Inscreve-se no paradigma do Nós em que interage com as antecedências humanas, hodiernas e vindouras, na qual os elementos da dinâmica cosmológica não estão fora, intrinsicamente, dentro do Nós-Ser.

\section{O que significa a pergunta: O que éramos, o que fizeram de nós e o que poderemos voltar vir a ser?}

Ser africano/afrodiaspórica/o ou nativo de culturas antigas da humanidade e que, por conseguinte, foram invadidas, subalternizadas nas suas existencialidades primordiais, que o racismo colonial com sua perpetração de ações como 0 apagão e o arrastão ideológico destruiu (HENRIQUES, 2017). À essas populações sobreviventes ou remanescentes desse processo do racismo colonial implicam elaborar essa problematização, por uma questão mesmo de sobrevida nas dispersões transatlântica, em particular, e buscar encontrar nuances afrofilosóficas existenciais de forma a recobrar a dignidade sustentada no autoconceito, autoimagem Existencial e, por conseguinte autoestima ontológica cuja enunciação pública seja plena.

\section{Como o senhor entende a xenofilia?}

Xenofilia ${ }^{33}$ é um pressuposto do 'berço civilizatório matricial' (MOORE, 2012) do 'berço meridional, segundo Cheikh Anta Diop os povos africanos atuam no

\footnotetext{
${ }^{33}$ Para melhor compreender o que o professor Jayro quer dizer com o termo xenofilia recomenda-se a leitura das teses de Cheikh Anta Diop. Em seu livro Racismo \& Sociedade, Moore (2007, p.148-150) diz que "A tese central de Diop está contida numa frase: 'A história da humanidade permanecerá na escuridão até que seja vislumbrada a existência de dois grandes berços - o meridional, que inclui toda a África setentrional, que corresponde ao espaço euroasiático - onde o clima forjou atitudes e mentalidades específicas' [...]. Diop limita analiticamente o 'berço meridional' no Continente Africano, mas infere que esse termo cobre uma grande zona do planeta antes das invasões euro-semitas e sino-nipônico-mongóis. A esse 'berço' corresponderiam, de maneira geral, características socioculturais forjadas pela vida comunal e por valores ético-morais enraizados na prática de solidariedade, como base da cooperação social. Segundo ele, esse berço 'é caracterizado pela família matriarcal e a criação do estado territorial, em contraste com a cidade-Estado ariana [indo-europeia]'[...]. Essas estruturas se basearam, essencialmente, na concetricidade social horizontal, na policonjugalidade, na matricentricidade e na propriedade comum do solo. Elas são regidas por complexas redes de inter-relação social subordinadas ao conceito de dever-obrigação como base da conduta individual e coletiva.

No berço civilizatório 'meridional', a mulher goza de uma posição de destaque na comunidade, sendo ela emancipada da vida doméstica. O caráter feminino desse tipo de sociedade, fortemente uterocêntrica, voltada para a cooperação solidária, teria secretado uma percepção positiva da alteridade, de maneira a conceber o Outro - seja qual for - como parceiro, não como inimigo. Assim, a xenofilia, o cosmopolitismo e o coletivismo social são expressões específicas desse berço, tornando-se dados culturais intrínsecos. De acordo com Diop, essas características implicaram uma 'tranquilidade que conduz à despreocupação com o futura e uma solidariedade material de direito garantida para cada indivíduo. Isso faz com que a miséria
}

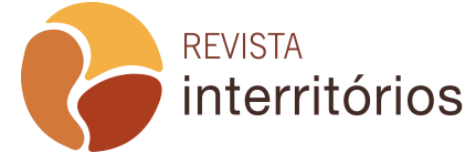

Interritórios | Revista de Educação Universidade Federal de Pernambuco, Caruaru, BRASIL | V.6 N.12 [2020] 
princípio da xenofilia e não da xenofobia (MOORE, 2012), evidentemente antagônico aos valores do berço setentrional ${ }^{34}$ (MOORE, 2012, p. 121), dinâmica social engendrada no Brasil que elegeu o atual presidente da República Jair Messias Bolsonaro, que em várias entrevistas deixou evidente seu pensamento machista, patriarcal e xenófobo. O princípio da xenofilia é aquele que agrega o Outro, um sujeito que num primeiro momento é diferente de mim, mas que é humano também. Os povos negros são agregadores, talvez seja um dos elementos que facilitou a colonização do continente africano.

O senhor mora na sede da Escola Aldeia Ubuntu Vale do Akòko, zonal rural da região metropolitana de Salvador (BA), no município de Mata de São João. Como é a realidade dos meninos e meninas negras aí onde o senhor mora? Que tipo de escola esses meninos e meninas precisam?

Nascido na llha de Itaparica, igualmente de nascimento afrodiaspórico, região metropolitana de Salvador (BA), situada na Bahia de todos os santos, parte da llha em meio ao oceano atlântico, aos 13 para os 14 anos fui embora da ilha para estudar em seminários católicos. Ao abandonar o seminário atuei com educação primária, assim chamada na época, no distrito de Santiago do Iguape, município de cacheiro, no Recôncavo Baiano e em seguida no Curuzú/Liberdade na capital soteropolitana. Em seguida sair Brasil afora. Ficando fora da Bahia, por aproximadamente quarenta anos. Sofri dois acidentes

material e moral seja desconhecida até os dias atuais. Embora haja pessoas vivendo na pobreza, ninguém se sente só ou angustiado'. (MOORE, 2007, p.150).

${ }^{34}$ Moore (2005, p.151-152) citando Diop (1974), informa que o universo euro - asiático, denominado por Diop como berço setentrional' - configurado pela Europa mediterrânea, mas englobando também o Oriente Médio semita -, surgiu como uma espécie de antinomia evolutiva, suscitada pelas duras condições de vida em regiões geladas, nas quais as populações ancestrais dos europeus e dos semitas (proto-europeu-semitas) se viram constrangidas a existir durante um longo período de tempo. Nas estepes euro - asiáticas, explicou Diop, a vida esteve constantemente em perigo devido ao rigor do clima; o solo gelado impediu a transição para a agricultura e prolongou a dependência da caça; as temperaturas extremamente baixas constrangeram o homem a morar em lugares fechados e ase vestir abundantemente. Esse berço se erigiu, portanto, em torno de estruturas de competição, de hábitos materialistas, da prática da guerra, da conquista, do militarismo, do culto da propriedade privada e da visão xenófoba. Estamos diante de sociedades profundamente patricêntricas, falocráticas e intolerantes perante qualquer outra forma de alteridade; sociedades que menosprezam o input feminino.

Diop considera o mundo o mundo greco-romano como sendo prototípico das estruturas surgidas do berço 'setentrional', e que seria caracterizado, contrariamente ao processo 'meridional', pela família patriarcal e pela cidade-Estado. O lugar central ocupado pelo homem, somado à qualidade patriótica das cidades-Estado greco-romanas, estabelece a combinação que contribui para a concepção do Outro como ser estranho. Diante desse, o mundo euroasiático se concebeu num enfrentamento permanente. Com efeito, a assunção da noção de estrangeiro como um fora-da-lei gerou, explica Diop, um sentimento de patriotismo interno e, ao mesmo tempo, o sentimento de medo e repulsa pelo Outro. A xenofobia configurou-se como um dado imanente das sociedades que se constituíram nesse berço civilizatório. Os desdobramentos disso foram a 'solidão material e moral, desgosto pela vida e o individualismo.'

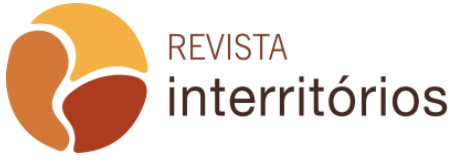


vasculares cerebrais (AVC) que ocasionaram severas sequelas, me levando a condição de cadeirante, resultando inclusive na minha aposentadoria por invalidez. Esse fato fez com que eu retornasse à Bahia. Precisei sair às pressas da cidade de Florianópolis (SC) porque fui ameaçado de morte durante 0 processo eleitoral. Ao articular minha saída da capital catarinense, decidi que não voltaria a residir não em grandes centros urbanos, estrategicamente optei pela zonal rural da região metropolitana de Mata de São João, resido no espaço da Escola Aldeia Ubuntu Vale do Akòko, uma escola em construção.

No bairro de Amado Bahia, a localização é majoritariamente habitada por população preta de cuja contingente populacional é composta por uma grande quantidade de crianças, adolescentes e jovens, destacando-se um número expressivo de mulheres e jovens na sua maioria pretos organizados em diversas facções e alta incidência de gravidez, fruto dos relacionamentos das meninas com os meninos pretos, invariavelmente das facções. $O$ fato da quantidade de mulheres gravidas cada vez mais aumentar, resultando em nascimentos sucessivos de crianças sem estrutura de lar me fez pensar que a elaboração e execução de um projeto de educação que se inicie como um processo préancestrálico intrauterino gestacional em mulheres pretas seja absolutamente imperativo, bem como um projeto afropedagógico afrocentrado que trabalhe a concepção ancestrálica como edificadora de uma outra comportamentalidade existencial capaz de conferir autoconceito, autoimagem e autoestima e que incida contra o semiocídio ontológico, bem como contra o genocídio físico, levando as crianças (meninas e meninos) pretas/os das periferias a compreenderem a abissal diferenças entre os dois "berços civilizatórios matricial" (MOORE, 2012), possibilitando a construção de um projeto biomíticosocial porque na minha compreensão o ser mulher ou homem respeitando a Tradição Africana significa conhecer sua contribuição civilizatória no engendramento da existência humana.

Esse processo que chamo de cosmologização do ser humano precisa ter início quando a criança ainda está sendo gestada no útero da mãe porque nesse momento ainda está ligada ao Todo, depois que que ela nasce é preciso que outro "útero mítico" se restabeleça para que ela retome a ligação com o Todo e a escola também pode ser o lugar dessa reconstrução.

\section{REFERÊNCIAS}

ALBUQUERQUE JUNIOR, D. M. de. João José Reis. Domingos Sodré, um sacerdote africano: escravidão, liberdade e candomblé na Bahia do século XIX. Revista

Brasileira de História. São Paulo, v.29, n.57, p.211-217, 2009.

ALMEIDA, S. L. de. Racismo estrutural. São Paulo: Sueli Carneiro; Pólen, 2019.

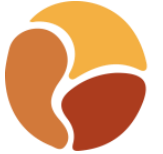


CARNEIRO, S. Racismo, sexismo e desigualdade no Brasil. São Paulo: Selo Negro, 2011.

CUNHA, J. M. V. Conselho do povo de terreiro do estado do Rio Grande do Sul CPTERS: protagonismo e ação política do movimento do povo de terreiro do RS. Trabalho de Conclusão de Curso (Graduação). 78f. Universidade Federal do Rio Grande do Sul, Instituto de Ciências Sociais, Porto Alegre (RS), 2018.

DUSSEL, E. Ética da libertação: na idade da globalização e da exclusão. In: SOUSA, S, B. de; MENESES, M. P. (Orgs.). Epistemologias do sul. São Paulo: Cortez, 2010.

FANON, F. Os condenados da terra. 2. ed. Rio de Janeiro: Civilização Brasileira, 1979.

HENRIQUES, J. G. Racismo em português: o lado esquecido do colonialismo. 1. ed. Rio de Janeiro: Tinta-da-China Brasil, 2017.

JESUS, J. P. de. Terreiro e cidadania: um projeto de combate ao racismo cultural religioso afro e de implementação de ações sociais em comunidades-terreiros. In: Ashoka Empreendedores Sociais; Takano Cidadania (Orgs.). Racismos contemporâneos. 1. ed. Rio de Janeiro: Takano, 2003.

KABWASA, N. O. O eterno retorno. In: O Correio da Unesco (Brasil), dez. 1982, ano 10, n.12, p.14 -15 .

KASHINDI, J-B. K. Ubuntu como ética africana, humanista e inclusiva. Disponível em:

http://www.ihu.unisinos.br/images/stories/cadernos/ideias/254cadernosihuideias.pdf. Acesso em: 21/09/2020.

MOORE, C. Racismo \& Sociedade: novas bases epistemológicas para entender o racismo. 2ª ed. Belo Horizonte: Nandyala, 2012.

NASCIMENTO, E. L. (Org.). Sankofa I: As matrizes africanas na cultura brasileira. A matriz africana no mundo. São Paulo: Selo Negro, 2008.

QUIJANO, A. La nueva heterogeneidade estructural de América Latina em Sonntag. In: HEINZ (Ed.). Nuevos temas, nuevos contenidos. Caracas: UNESCO/Nueva Sociedade, 1989.

QUIJANO, A. A colonialidade do poder. In: SANTOS, B. de S.; MENESES, M.P. (Orgs). Epistemologias do sul. Coimbra: Gráfica de Coimbra, Ltda: 2009.

SARDELOTTO, M.; SANDER, L. M. Ser por meio dos outros: o ubuntu como cuidado e partilha. Revista do Instituto Humanitas Unisinos, ano X, dez.,2010, p.8-9. Disponível em:

file:///C:/Users/Usu\%C3\%A1rio/Documents/PROFCIAMB\%202020/POVOS\%20E\%20 COM\%20TRAD/Cadernos_Unissinos_1.pdf. Acesso em: 22/09/2020.

SANTOS, J. E. dos. Os Nagô e a morte: pàde, àsèsè e o culto égun na Bahia. 5a. ed. Universidade Federal da Bahia, Salvador (BA): Vozes, 1986.

SODRÉ, M. A verdade seduzida. 3.ed. Rio de Janeiro: DP\&A, 2005. 
SODRÉ, M. Reinventando a educação: diversidade, descolonização e redes. 2. Ed. Petrópolis (RJ): Vozes, 2012.

SODRÉ, M. O terreiro e a cidade: a forma social negro-brasileira. $3^{\underline{a}}$ ed. Rio de Janeiro: Mauad X, 2019.

SODRÉ, M. Pensar nagô. 3. ed. Petrópolis (RJ): Vozes: 2020. 